\section{Acknowledgements}

Thanks to all the members of the team for their forbearance. I dedicate this article to the memory of the late Dennis McCourt, a social worker at Charing Cross Hospital.

\section{References}

APPLEBY, L. (2000) Safer services: conclusions from the report of the National Confidential Inquiry. Advances in Psychiatric Treatment, 6, 5-15.

BITTNER, E. (1967) Police discretion in emergency apprehension of mentally ill persons. Social Problems, 24 $278-292$.

GIRGIS, S. \& SPENCE, S. (2003) Is it worth treating mentally ill roofless people? Schizophrenia Research, 60 (suppl.), 284-285.
JAFFEE, S. R., MOFFITT, T. E., CASPI, A., et al (2003) Life with (or without) father: the benefits of living with two biological parents depend on the father's antisocial behaviour. Child Development, 74, 109-126.

LIVINGSTONE-SMITH, D. (2004) Why We Lie. The Evolutionary Roots of Deception and the Unconscious Mind. St Martin's Press.

MAGUIRE, N. (2006) Cognitive behavioural therapy and homelessness: a case series pilot study. Behavioural and Cognitive Psychotherapy, 34, 107-111.

MITCHELL, A. J. \& SELMES,T. (2007) Why don't patients attend their appointments? Maintaining engagement with psychiatric services. Advances in Psychiatric Treatment, 13, 423-434.

NELSON, H. E. \& O'CONNELL, A. (1978) Dementia: the estimation of premorbid intelligence levels using the NewAdult Reading Test. Cortex, 14, 234-244.

PHILLIPS, A. (1988) Winnicott. Fontana.

SPENCE, S., STEVENS, R. \& PARKS, R.

(2004) Cognitive dysfunction in

homeless adults: a systematic review. Journal of the Royal Society of Medicine, 97, 375-379.
SUMMERFIELD, D. (2002) Commentary. Advances in Psychiatric Treatment, 8 247-248.

THOMAS, S. \& SPENCE, S. (2005) In bed at midday: missing lunch on an acute psychiatric ward. Poster and abstract presented at Annual Meeting of the Royal College of Psychiatrists, Edinburgh 20 June 2005 [available on CD].

TIMMS, P. (1996) Management aspects of care for the homeless mentally ill. Advances in Psychiatric Treatment, $\mathbf{2}$, $158-165$.

TRIBE, R. (2002) Mental health of refugees and asylum-seekers. Advances in Psychiatric Treatment, 8 , $240-247$.

Sean A. Spence Professor of General Adult Psychiatry, University of Sheffield, The Longley Centre, Norwood Grange Drive, Sheffield S5 7JT, UK, email: S.A.Spence@Sheffield.ac.uk

\title{
KATE LATIMER
}

\section{Mental Health (Care and Treatment) (Scotland) Act 2003: impact on child and adolescent in-patient services}

\section{SUMMARY}

This article examines the recommendations in The Mental Health (Care and Treatment) (Scotland) Act 2003 that are related to child and adolescent psychiatric services. Statistics relating to the first 6 months of the Act are included to indicate how it is being implemented and enable conclusions to be reached on how the Act is working in practice at this early stage.
In recent years there have been a number of reports looking at ways of improving mental health services for children and adolescents. In 2001, the Scottish Executive set out its plans for improving children's services and promoting collaboration in its report For Scotland's Children (Scottish Executive, 2001). This was followed in 2003 by the SNAP (Scottish Needs Assessment Programme) report on child and adolescent health (Public Health Institute of Scotland, 2003). It looked at the planning and delivery of services. Following the SNAP report, the Scottish Executive (2003), in conjunction with the Child Health Support Group, produced Children and Young People's Mental Health: A Framework for Promotion, Prevention and Care. As part of this framework, a commitment was made to increase adolescent in-patient beds as well as the development of community services in order to reduce the number of admissions of children and young people to adult beds by $50 \%$ by 2009 . The framework was launched in October 2005 and at the same time the Mental Health (Care and Treatment) (Scotland) Act 2003 was implemented.

\section{The Mental Health (Care and Treatment) (Scotland) Act 2003}

The Act applies to people with a 'mental disorder'. This term is used to cover mental health problems, personality disorders and learning disabilities. The Act contains a number of recommendations surrounding the care and treatment of children and adolescents with mental disorders being treated in hospital. This provides added legal weight to the need to improve services in Scotland.

One of the important changes from the old 1984 Scottish Mental Health Act is that the new Act is based on a set of ten guiding principles that should be considered by anyone using the new Act. These are:
1. non-discrimination
2. equality
3. respect for diversity
4. reciprocity
5. informal care
6. participation
7. respect for carers
8. least restrictive alternative

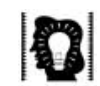

special articles 
9. benefit

10. child welfare.

special articles
The principle of child welfare requires that any functions under the Act in relation to a child (defined as a person under 18 years) with a mental disorder should always be carried out in a manner that best secures the welfare of the child. The code of practice suggests that it is necessary to take into account:

- the wishes and feelings of the child and the views of any carers;

- the carer's needs and circumstances which are relevant to the discharge of any function;

- the importance of providing any carer with information as might assist them to care for the individual;

- where the child is or has been subject to compulsory powers, the importance of providing appropriate services to that child;

- the importance of the function being discharged in the manner that appears to involve the minimum restriction on the freedom of the child as is necessary in the circumstances.

\section{Number of children and adolescents detained}

The Mental Welfare Commission (2006a) has published statistics for the first 6 months of the new Act. These show that 29 under-18-year-olds were placed on emergency detention certificates. An emergency detention lasts for $72 \mathrm{~h}$. Any registered medical practitioner may grant an emergency detention. The individual has no formal right of appeal against the granting of an emergency detention. The 29 under-18-year-olds detained accounted for about $3 \%$ of all emergency detentions. The majority of the emergency detention certificates were for adolescents in the 16 to 17 -year-old age range (86\%). Forty-two under-18s were placed on short-term detention certificates. A short-term detention lasts for 28 days and may only be granted by an approved medical practitioner. Both the individual and the individual's named person have a right to appeal against the short-term detention. Again, the under-18-year-olds accounted for about $3 \%$ of all short-term detention certificates. A comparison with the last 6 months of the old Act showed that 39 under-18s were placed on an emergency detention during the period April-December 2005. However, this was out of a much higher total and so only accounted for $1 \%$ of all emergency detentions granted. Short-term detentions show that 28 under-18s were detained - around $2 \%$ of the total detentions. Unfortunately, there is not yet information on longer-term detentions. Compulsory treatment orders can be applied for by a mental health officer. The application consists of two mental health reports prepared by medical practitioners, the mental health officer's report and a proposed care plan. If the tribunal grants the compulsory treatment order it lasts for 6 months.

\section{Children at risk}

The Mental Health (Care and Treatment) (Scotland) Act 2003 does not cover children at risk. If there are concerns about the safety of a child then the Children (Scotland) Act 1995 must be used. Unlike the Mental Health (Care and Treatment) (Scotland) Act 2003, the Children (Scotland) Act 1995 defines a child as being under 16. The Children (Scotland) Act 1995 covers laws relating to children, to the adoption of children and to young persons who as children have been looked after by a local authority. The Children (Scotland) Act 1995 can be used to enable local authorities to apply for a Child Protection Order or Child Assessment Order. Also, any person with concerns about a child can refer the matter to a children's reporter enabling the concerns to be investigated.

The Protection of Children (Scotland) Act 2003 also has a role in looking after children at risk. The Act requires Scottish Ministers to keep a list of individuals whom they consider to be unsuitable to work with children; to prohibit individuals included in the list, and individuals who are similarly regarded in other jurisdictions, from doing certain work relating to children; to make further provision in relation to that list and for connected purposes.

Neither of the above two Acts make direct provision for the care and treatment of children suffering from mental illness unlike the Mental Health (Care and Treatment) (Scotland) Act 2003.

\section{Health board provision for young people}

There are a number of safeguards that have been brought into the new Mental Health (Care and Treatment) (Scotland) Act 2003 to protect the rights of mental health service users. Some of these safeguards will benefit all service users and not just people who are being treated under the Act. One of these safeguards is that health boards will have to provide services for children and young people (aged under 18) that are appropriate for their particular needs. The Act recommends that it is best practice to admit a child to a unit specialising in child and adolescent psychiatry. The Act also highlights the fact that educational authorities have a duty to make arrangements for the education of pupils unable to attend school either because they are subject to the measures authorised by the Act, or in consequence of their mental disorder.

\section{Guidelines for the admission of young people to adult mental health wards}

Unfortunately at present, because of a lack of resources, it may not always be possible to admit a detained child to a specialist child and adolescent unit. In these cases the Act recommends that any risks to the child need to be identified and a plan put in place to minimise them. For example, it may be that the child requires a single room or special monitoring arrangements. The code of practice 
for the Act states that particular consideration should be given to the likely impact on the child of the behaviour of other patients on the ward and the need to protect such children from exposure to distressing experiences. Other ward policies, such as visiting, may also need to be modified. The code also recommends that nursing staff with experience of working with children should be available to provide direct input to the care of the child, and to give support and guidance to ward staff.

In the event of a child patient being admitted to an adult ward, it is considered best practice for the hospital managers to notify the Mental Welfare Commission to enable them to monitor the general provision of age appropriate services under the Act. In January 2006, the Mental Welfare Commission brought out guidelines on the admission of young people to general adult wards. The guidelines that the Commission (2006b) expects to be adhered to are as follows.

1. The particular needs of each young person be central to decisions about admission and management. The needs of families and carers must also be taken into account.

2. Every effort be made to provide for age-appropriate specialist care. This should include a child and adolescent psychiatrist taking consultant responsibility where at all possible; nursing staff with experience of working with young people being available to provide input to ward staff; and access being available to other local child and adolescent services.

3. There must be attention to the needs of young people in terms of their protection and welfare within a ward environment that is designed for adults. The Commission notes that this is especially important in an admission to an intensive psychiatric care unit and must include an awareness of the young person's potential physical, emotional and sexual vulnerability.

4. There should be access to appropriate therapeutic and recreational activities as well as an awareness of educational needs.

5. Staff need to be aware of the legal context of a young person's admission and treatment.

6. If possible, a particular ward be identified within an adult in-patient service to receive young people's admissions. This allows a particular group of medical and nursing staff to become more familiar with the needs of young people.

\section{Figures for under-18s admitted to psychiatric in-patient services}

As discussed above, it is considered best practice to inform the Mental Welfare Commission when young people are admitted to non-specialist facilities. Figures have now been produced showing that in the first 6 months of the new Act there were 69 cases of young people being admitted to non-specialist facilities (Mental Welfare Commission, 2006b). The Commission received information about 59 of these cases. This shows that the guidelines are not being followed in all cases.
- $34 \%$ of the cases had a consultant that was a child and adolescent specialist.

- $34 \%$ had nursing staff with experience of young people working directly with them.

- $64 \%$ had nursing staff with experience of working with young people able to provide advice to ward staff.

- $42 \%$ had access to other age-appropriate therapeutic input.

- $59 \%$ had access to age-appropriate recreational activities.

- $29 \%$ had a discussion about their educational needs.

It should be noted that the available statistics contain some uncertainty as detailed information has not been provided in $14 \%$ of cases. However, it is clear that the resultant uncertainty because of this relatively small omission cannot account for the large figure of underachievement.

\section{Conclusion}

The Mental Health (Care and Treatment) (Scotland) Act 2003, in conjunction with some Scottish Executive reviews, has resulted in the introduction of a number of recommendations intended to improve the standard of child and adolescent psychiatric care in Scotland. Data gathered indicates that there is still much room for improvement. Many, and in some cases the majority of, individuals are clearly still not receiving age-appropriate services as required under the new Act.

Government proposals to increase beds in specific child and adolescent units will help to improve the situation in the longer term. However, there is an urgent need to ensure that the principles of the new Act and the Mental Welfare Commission guidelines are acknowledged and acted upon by all relevant personnel involved in the care of child and adolescent in-patients.

\section{Declaration of interest}

None.

\section{References}

MENTALWELFARE COMMISSIONFOR PUBLIC HEALTH INSTITUTE OF SCOTLAND (2006a) OurAnnual Report SCOTLAND (2003) Scottish Needs 2005-2006, a New Year a New Law. Assessment Programme (SNAP). NHS Mental Welfare Commission for Scotland.

MENTAL WELFARE COMMISSIONFOR SCOTLAND (2006b) Mental Welfare Commission Guidance on the Admission of Young People to Adult Mental Health Wards. Mental Welfare Commission for Scotland. Scotland. SCOTTISH EXECUTIVE (2001) For Scotland's children. Better integrated services. Scottish Executive.

SCOTTISHEXECUTIVE (2004) Children and Young People's Mental Health: a framework for promotion, prevention and care. Scottish Executive.

Kate Latimer ST4 Child and Adolescent Psychiatry, The Manor, Brown Street, Falkirk FK1 4PX, UK, email: katelatimer@doctors.org.uk special articles 